\title{
DIFERENTES ESPAÇAMENTOS DE PLANTIO E NÍVEIS DE ADUBAÇÃO SOBRE A ATIVIDADE DA REDUTASE DO NITRATO EM FOLHAS DO HÍBRIDO DE MAMOEIRO UENF/CALIMAN-01 ${ }^{1}$
}

\author{
RENATA VENTURIM FONTES ${ }^{2}$, ALEXANDRE PIO VIANA ${ }^{3}$, MESSIAS GONZAGA PEREIRA ${ }^{3}$, \\ JURANDI GONÇALVES DE OLIVEIRA ${ }^{3}$, DIOLINA MOURA SILVA ${ }^{4}$, \\ SABRINA GARCIA BROETTO 5 , MARIELA MATTOS DA SILVA ${ }^{6}$
}

RESUMO - O objetivo deste trabalho foi avaliar o efeito de diferentes espaçamentos de plantio e de níveis de adubação NPK sobre a atividade da redutase do nitrato (RN) nas folhas do híbrido de mamoeiro UENF/ CALIMAN-01, visando a sugerir possível ajuste em seu manejo de adubação nitrogenada, no sentido de maximizar a eficiência do uso do nitrogênio. O experimento foi conduzido na fazenda Caliman Agrícola S.A., no município de Linhares - ES. Utilizou-se o delineamento estatístico experimental em blocos casualizados, com esquema fatorial, com três espaçamentos de plantio entre plantas $(\mathrm{E} 1=1,8 \mathrm{~m} ; \mathrm{E} 2=2,25 \mathrm{~m}$, e E3 $=2,7$ $\mathrm{m}$ ), cinco níveis de adubação NPK convencional (A1 $=80 \%$ do padrão; $\mathrm{A} 2=100 \%$ padrão da empresa; A3 $=120 \%$ do padrão; $\mathrm{A} 4=140 \%$ do padrão, e A5 $=160 \%$ do padrão) e cinco períodos de avaliação (meses de março a julho). O padrão de adubação NPK da empresa consiste em 350; 105 e $660 \mathrm{~kg} \mathrm{ha}^{-1} \mathrm{ano}^{-1}$ de sulfato de amônio $(20 \%$ de $\mathrm{N})$, superfosfato simples ( $18 \%$ de $\mathrm{P})$ e cloreto de potássio $(60 \%$ de $\mathrm{K})$, respectivamente. Os dados obtidos para a atividade da RN foram submetidos a uma análise de variância e teste de médias. Dentre os tratamentos testados, o nível A1 ( $80 \%$ do padrão), independentemente do espaçamento, poderia ser indicado no manejo do híbrido de mamoeiro UENF/CALIMAN-01, pois em todos eles a atividade da redutase do nitrato, em praticamente todos os períodos avaliados, apresentou valores adequados, ou até mesmo superiores aos encontrados na literatura em cultivares de mamoeiro. A redução da adubação NPK pôde ser justificada, uma vez que não houve diferença na produtividade das plantas entre os tratamentos avaliados. Termos para indexação: mamão, espaçamento, adubação, redutase do nitrato.

\section{DIFFERENT PLANTING SPACINGS AND FERTILIZATION LEVELS ON THE ACTIVITY OF NITRATE REDUCTASE IN LEAVES OF PAPAYA HYBRID UENF/CALIMAN-01}

\begin{abstract}
The objective of this work was to evaluate the effect of different planting spacings and levels of NPK manuring on the activity of the nitrate reductase (NR) in the leaves of the papaya hybrid UENF/ CALIMAN-01, aiming to suggest possible adjustment in the handling of nitrogen fertilization, in the sense of maximizing the efficiency of the use of the nitrogen. The experiment was driven in the Caliman Agrícola S.A. farm, in the municipal district of Linhares- ES. A complete block design, factorial, with three planting spacings among plants $(\mathrm{E} 1=1.8 \mathrm{~m}, \mathrm{E} 2=2.25 \mathrm{~m}$ and $\mathrm{E} 3=2.7 \mathrm{~m})$, five levels of NPK conventional manuring (A1 $=80 \%$ of the standard, A2 $=100 \%$ of the company standard, A3 $=120 \%$ of the standard, A $4=140 \%$ of the standard and A5 $=160 \%$ of the standard) and five evaluation periods ( from March to July) was used. The standard of the company NPK manuring consists of 350, 105 and $660 \mathrm{Kg} \mathrm{ha}^{-1} \mathrm{year}^{-1}$ of sulfate of ammonium $(20 \%$ of $\mathrm{N})$, simple superphosphate ( $18 \%$ of $\mathrm{P})$ and potassium chloride ( $60 \%$ of $\mathrm{K})$, respectively. The data obtained for the activity of NR were submitted to a variance analysis and average test. Among the tested treatments, A1 ( $80 \%$ of standard), independent of the spacing, could be indicated in the handling of the hybrid UENF/CALIMAN-01, because in all of them the activity of the nitrate reductase in, practically, all of the appraised periods, presented appropriate values, or even, superiors to the ones found in the literature for the papaya tree. The reduction of NPK fertilization could be justified, once that did not have difference in the productivity of the plants among the evaluated treatments.

Index terms: papaya, spacing, fertilizer, reductase of the nitrate.

\footnotetext{
1(Trabalho 273-09). Recebido em: 07-12-2009. Aceito para publicação em: 17-09-2010. Parte da tese de doutorado da primeira autora ${ }^{2}$ Bolsista de Pós-doutoramento/CAPES, DSc. em Produção Vegetal, PPGBV/UFES. Vitória-ES. rvfontes@yahoo.com.br ${ }^{4}$ Prof. Associado, DSc. em Fisiologia Vegetal, PPGBV/UFES. biovegetal@terra.com.br;

${ }^{5}$ Doutoranda no Departamento de Alimentos e Nutrição Experimental/USP. sabroetto@yahoo.com.br;

${ }^{6}$ Doutoranda em Fisiologia Vegetal/UFV. marielamtts@yahoo.com.br
}

3Prof. Associado, Lab. de Melhoramento Genético Vegetal - CCTA/LMGV/UENF. pirapora@uenf.br; messias@uenf.br; jugo@uenf.br
\end{abstract}




\section{INTRODUÇÃO}

O nitrogênio é o segundo nutriente mais exigido pelo mamoeiro, fomentando o seu crescimento vegetativo. A exigência do mamoeiro em relação a este nutriente é crescente e constante em todo o ciclo, sendo muito importante seu suprimento nos seis primeiros meses de vida da planta. Neste período, uma faixa de $23 \%$ do total de nitrogênio absorvido é exportada para as flores e frutos (LYRA, 2007). Dada a sua importância e a alta mobilidade no solo, o nitrogênio tem sido intensamente estudado, no sentido de maximizar a eficiência do seu uso. Para tanto, tem-se procurado diminuir as perdas do nitrogênio no solo, bem como melhorar a absorção e a metabolização do nitrogênio no interior da planta (BREDEMEIER; MUNDSTOCK, 2000).

O nitrato é a principal forma de nitrogênio disponível para as plantas após a calagem e adubações em plantios comerciais. Para que esse íon seja incorporado a compostos orgânicos no sistema radicular e na parte aérea, deve ser reduzido a amônio $\left(\mathrm{NH}_{4}^{+}\right)$(ANDRADE NETTO, 2005; FONTES et al., 2008). Após a absorção do nitrato pelas raízes, inicia-se o processo de assimilação do nitrogênio. Segundo Ferreira et al. (2002), este processo é vital, pois controla o crescimento e o desenvolvimento das plantas, e tem efeitos marcantes sobre a fitomassa e a produtividade final das culturas. A taxa e a quantidade de nitrogênio assimilado pelas plantas durante o seu ciclo dependem da atividade das enzimas envolvidas no ciclo do nitrogênio e da disponibilidade de energia necessária para os processos de assimilação (BREDEMEIER; MUNDSTOCK, 2000).

O primeiro passo do processo de assimilação do nitrogênio é realizado pela redutase do nitrato (RN), enzima que catalisa a transformação do nitrato $\left(\mathrm{NO}_{3}^{-}\right)$em nitrito $\left(\mathrm{NO}_{2}^{-}\right)$no citossol. A RN é considerada a enzima-chave no processo de absorção do nitrogênio, pois catalisa o primeiro passo na via de redução do nitrato (FONTES et al., 2008). O nitrito formado pela ação catalisadora da $\mathrm{RN}$ é posteriormente transformado em amônio $\left(\mathrm{NH}_{4}^{+}\right)$pela ação da redutase do nitrito. $\mathrm{O}$ amônio produzido é então incorporado em ácidos orgânicos, dando origem aos aminoácidos, a partir de reações subsequentes catalisadas pelas enzimas glutamina sintetase (GS) e glutamato sintase (GOGAT) (DONATO et al., 2004). A GS catalisa a conversão do aminoácido glutamato (Glu) para a amida glutamina (Gln) enquanto a GOGAT catalisa a transferência redutiva do $\mathrm{N}$-amídico da GLN para o 2-oxoglutarato, para formar dois Glu (ANDRADE NETTO, 2005).

A metodologia in vivo de análise da $\mathrm{RN}$ oferece uma estimativa satisfatória da redução do íon nitrato in situ, possibilitando a quantificação do nitrito produzido por células intactas de pequenos segmentos de tecidos vegetais e tem sido amplamente utilizada como indicadora do metabolismo do nitrogênio nos vegetais, sendo considerada por muitos autores como a mais adequada para a comparação da atividade da redutase do nitrato entre espécies diferentes ou entre tratamentos distintos (NIEVOLA;MERCIER, 2001).

$\mathrm{Na}$ literatura, são escassos os trabalhos que relacionam a atividade da redutase do nitrato com o período de avaliação, com o manejo de espaçamento de plantio ou com o manejo de adubação NPK em espécies cultivadas, a exemplo do mamoeiro. Dessa forma, este trabalho teve o objetivo de avaliar o efeito de diferentes espaçamentos de plantio e de níveis de adubação NPK, bem como do período de avaliação, sobre a atividade da redutase do nitrato em folhas do híbrido de mamoeiro UENF/CALIMAN-01, visando a sugerir possível ajuste em seu manejo de adubação nitrogenada, no sentido de maximizar a eficiência do uso do nitrogênio.

\section{MATERIAL E MÉTODOS}

O experimento foi conduzido na Fazenda Caliman Agrícola S/A, localizada no município de Linhares, norte do Estado do Espírito Santo, cujas coordenadas geográficas são $19^{\circ} 10^{\prime}$ de latitude sul e $39^{\circ} 50^{\prime}$ de longitude oeste e altitude de 30m (MARINHO, 2007). A precipitação pluviométrica anual é de $1.250 \mathrm{~mm}$, a temperatura média de $23{ }^{\circ} \mathrm{C}$ e a umidade relativa do ar de $83,5 \%$ (ROLLIM et al., 1999; SIAG/Incaper, 2006).

Aárea experimental possui solo com fertilidade natural baixa, entretanto não apresenta restrições para o uso agrícola nem necessidade de práticas especiais de manejo para controle de erosão (GOMES FILHO, 2005).

O sistema de irrigação adotado para o experimento foi o de microaspersão, sendo um mesmo microaspersor utilizado para quatro plantas. Neste sistema, a água é aplicada diretamente sobre a região radicular, com pequena intensidade e alta frequência (turno de rega de 1 a 5 dias), de modo a manter a umidade do solo na zona radicular próxima à capacidade de campo (BERNARDO et al., 1996).

O delineamento experimental adotado foi o de blocos casualizados, em arranjo fatorial, com quinze tratamentos e quatro repetições. Adotou-se o sistema de fileiras duplas com o espaçamento fixo entre fileiras duplas de 3,6 $\mathrm{m}$ e de 2,0 $\mathrm{m}$ entre as fileiras que compunham a fileira dupla. Entre plantas dentro 
de fileiras duplas, foram testados três espaçamentos: $\mathrm{E} 1=1,8 \mathrm{~m}$ entre plantas $\left(30\right.$ plantas parcela $\left.^{-1}\right)$; E2 $=2,25 \mathrm{~m}^{2}$ entre plantas $\left(24\right.$ plantas parcela $\left.^{-1}\right)$, e E3 $=$ 2,7 m entre plantas (20 plantas parcela $\left.{ }^{-1}\right)$. $\mathrm{O}$ número variável de plantas entre os diferentes espaçamentos foi ajustado para que todas as parcelas tivessem a mesma área útil de plantio. Dentro de cada espaçamento, foram testados cinco níveis de adubação NPK convencional $(\mathrm{A} 1=80 \%$ do padrão; $\mathrm{A} 2=100 \%$ do padrão da empresa; A3 $=120 \%$ do padrão; A4 = $140 \%$ do padrão, e A5 $=160 \%$ do padrão). O padrão de adubação NPK da empresa consiste em 350; 105 e $660 \mathrm{Kg} \mathrm{ha}^{-1}$ ano $^{-1}$ de sulfato de amônio ( $20 \%$ de N), superfosfato simples $(18 \%$ de $\mathrm{P})$ e cloreto de potássio (60\% de $\mathrm{K})$, respectivamente.

A atividade da redutase do nitrato no mamoeiro UENF/CALIMAN-01 foi determinada em folhas jovens completamente expandidas e fisiologicamente maduras, cuja axila continha uma primeira flor aberta. Foi retirada uma amostra por parcela, totalizando 60 amostras por período avaliado (meses de março a julho). As folhas eram retiradas das plantas no campo e transportadas dentro de sacos plásticos pretos colocados em bolsa térmica com gelo e permaneciam nessas condições, por algumas horas, até o momento da chegada ao laboratório. Para a determinação da atividade da $\mathrm{RN}$, utilizou-se o método in vivo descrito por Jaworski (1971) com modificações feitas por Fontes et al. (2008). Este método baseiase no princípio de que a concentração de nitrito $\left(\mathrm{NO}_{2}^{-}\right)$liberada por fragmentos de tecidos foliares em uma solução tampão, na presença de um agente permanente (propanol), do substrato $\left(\mathrm{NO}_{3}^{-}\right)$e de um saponificador (triton), reflete a atividade potencial da RN in situ. Esse conjunto é então transferido para um dessecador, onde é mantido sob vácuo por um minuto, sendo essa operação repetida mais duas vezes. Em seguida, o frasco de incubação é levado para banho-maria, com agitação constante a $30^{\circ} \mathrm{C}$, no escuro. Amostras de $0,8 \mathrm{~mL}$ do extrato são retiradas do banho-maria após 40 minutos de incubação. Mistura-se a essas amostras $0,3 \mathrm{~mL}$ de sulfanilamida a $1 \%$ e $0,3 \mathrm{~mL}$ de $\mathrm{N}$-(1-napthly)-ethylenediamine dihydrochloride a $0,02 \%$, completando o volume para $5 \mathrm{~mL}$. Após uma hora de reação, a atividade da enzima é estimada pela quantidade de nitrito liberada na solução de incubação, medida em espectrofotômetro a $540 \mathrm{~nm}$, e expressa em nmoles de $\mathrm{NO}_{2}^{-} \mathrm{h}^{-1} \mathrm{~g}^{-1} \mathrm{de}$ matéria fresca.

Os dados obtidos foram submetidos à análise de variância, com teste $\mathrm{F}$ a 5\% de probabilidade, no programa SAS. Os graus de liberdade dos fatores em estudo foram desdobrados via teste de comparação de médias, utilizando-se para isto do teste de Tukey, a 5\% de significância, no programa GENES (CRUZ, 2006).

\section{RESULTADOS E DISCUSSÃO}

A análise de variância (Tabela 1) indicou efeito apenas do espaçamento, período de avaliação e interação entre espaçamento e período de avaliação sobre a atividade da redutase do nitrato $(\mathrm{RN})$. Entretanto, essas diferenças da atividade da RN não se apresentaram diretamente relacionadas aos níveis de adubo nitrogenado aplicado.

A atividade da redutase do nitrato variou entre os períodos de avaliação (Tabela 2), sendo que os maiores valores de atividade dessa enzima foram obtidos nos meses de março, maio e junho, valores superiores aos encontrados, por exemplo, por Fontes et al. (2008), trabalhando com plantas de mamoeiro das cultivares Tainung 01 e Sunrise Solo 72/12. Os menores valores obtidos para a atividade da RN, no presente estudo (abril e julho), estão próximos aos encontrados por Fontes (2003), Fontes (2005) e Fontes et al. (2008), que também trabalharam com mamoeiro, e por Donato et al. (2004), que determinaram a atividade desta enzima em plantas de cana.

A variação da atividade da redutase do nitrato nos diferentes períodos de avaliação, observada neste estudo, pode ser explicada pela influência de fatores variados. O ATP é requerido para a inativação da enzima $R N$, que ao ser fosforilada perde sua atividade (TAIZ; ZEIGER, 2006). O NADPH é utilizado como aceptor de elétrons e como cofator da reação de oxirredução que é mediada pela $\mathrm{RN}$, que converte o nitrato em nitrito (KAISER; HUBER, 2001). Os carboidratos fornecem energia para as reações endergônicas do processo, como a entrada do nitrato nas células (GALON; SILVA, 2001). Em contrapartida, a capacidade fotossintética das plantas é dependente do suprimento de nitrogênio, pois uma considerável fração desse elemento encontrase alocada nas folhas em proteínas e em pigmentos envolvidos diretamente no processo fotossintético (CARELLI et al., 1996; DONATO et al., 2004). Por essa razão, a capacidade fotossintética das plantas e o metabolismo do nitrogênio estão diretamente interligados. Esta relação entre a atividade da redutase do nitrato e a fotossíntese em plantas já foi observada por Huber et al. (1992) em espinafre, Fontes (2003) em mamoeiro cv. Sunrise Solo, por Andrade Netto (2005) em cafeeiro arábica e por Fontes (2005) e Fontes et al. (2008) em mamoeiro cv. Tainung $01 \mathrm{e}$ Sunrise Solo 72/12.

Assim, a atividade da redutase do nitrato apresentou os maiores valores nos meses de março, 
maio e junho, e os menores valores nos meses de abril e julho. Esses resultados poderiam ser explicados quando se verifica o valor de temperatura média, umidade relativa e de pluviosidade obtidos em cada mês (Tabela 3). Essas variáveis estão relacionadas diretamente ao processo fotossintético, como descrito anteriormente. Entretanto, em relação à temperatura média e à umidade relativa, em todos estes cinco meses de avaliação da atividade da $\mathrm{RN}$, não foram obtidos valores inadequados para o cultivo do mamoeiro, de acordo com os valores considerados adequados por Trindade (2000). Nos meses de março, maio e junho, onde a atividade da $\mathrm{RN}$ foi maior, os valores de pluviosidade apresentaram-se baixos. E nos meses de abril e julho, onde a atividade dessa enzima apresentou os menores valores, a pluviosidade foi muito alta no mês de abril e, ao contrário, muito baixa no mês de julho (Figura 1). Dessa forma, a quantidade de chuva não deve ter sido um dos fatores determinantes no comportamento da atividade da $\mathrm{RN}$ nas plantas de mamoeiro aqui avaliadas, devido, também, a cultura ter sido irrigada periodicamente.

$\mathrm{O}$ efeito do espaçamento de plantio na atividade da RN foi verificado no mês de março. No tratamento com adubação de $100 \%$ de NPK, a atividade da enzima foi menor no espaçamento E3 em relação ao valor obtido no espaçamento E1. Na adubação de $120 \%$ de NPK, o menor valor obtido para a atividade da enzima foi no espaçamento E2, e o maior valor, no espaçamento E1 (Tabela 2). Nestes dois casos, a atividade da RN foi maior nas plantas cultivadas mais adensadas, ou seja, com menor espaçamento de plantio entre elas. A mesma situação foi verificada no mês de abril (na adubação de $140 \%$ NPK), em que a atividade da redutase do nitrato foi maior nas plantas cultivadas no espaçamento E1 e menor naquelas cultivadas no espaçamento E2. Entretanto, na adubação de $160 \%$ de NPK, o maior valor para atividade da RN nas plantas do híbrido de mamoeiro UENF/ CALIMAN-01 foi observado no maior espaçamento entre plantas testado, espaçamento E3, enquanto o menor valor foi obtido no espaçamento E2. Apenas nesta situação, o comportamento da atividade enzimática da RN poderia ser explicado pelo fato de que a utilização de maior espaçamento de plantio reduziria a competição por luz, nutrientes e água. De acordo com Resende e Costa (2003), a densidade de plantio é um fator a ser levado em consideração, uma vez que as pressões exercidas pela população de plantas afetam de modo marcante seu crescimento e desenvolvimento. Isto porque, quando há um aumento do número de plantas por unidade de área, há também um aumento na competição por fatores essenciais de crescimento, como luz, nutrientes e água (SCARPARE FILHO; KLUGE, 2001).

Em maio e junho, verificou-se efeito do espaçamento entre plantas apenas dentro da adubação de $160 \%$ de NPK, em que o maior valor encontrado foi no espaçamento E1, e os menores valores, no espaçamento E2 (Tabela 2).

No mês de julho, apenas dentro da adubação de $140 \%$ de NPK, foi observado maior atividade da RN nos espaçamentos E1 e E2 em relação ao espaçamento E2 (Tabela 2).

Observa-se que, para a maioria dos meses avaliados (abril, maio e junho), o efeito do espaçamento na atividade da redutase do nitrato foi observado dentro do maior nível de adubação testado, que foi de $160 \%$ de NPK. Como não se observou diferença estatística da atividade da RN nos espaçamentos com menores níveis de adubação $(80 \%, 100 \%$ e $120 \%$ de NPK) e que os valores de atividade da enzima se encontraram adequados, ou até mesmo superiores aos já obtidos na literatura para cultivares de mamoeiro, resolveu-se optar pela sugestão de utilização do nível de $80 \%$ de NPK na adubação, uma vez que a produtividade das plantas não diferiu entre os tratamentos (dados não mostrados). Essa sugestão baseia-se na economia de gastos com adubo nitrogenado, bem como na minimização do impacto ao meio ambiente da utilização de altas doses de adubação contendo nitrogênio. Em relação à indicação do espaçamento mais adequado (E1, E2 ou E3), dentro da adubação de $80 \%$ de NPK, observa-se que, em todos eles, não houve diferença significativa na atividade da redutase do nitrato em todos os meses avaliados. Dessa forma, todos os três espaçamentos testados poderiam ser utilizados no manejo de adubação nitrogenada para o híbrido de mamoeiro UENF/CALIMAN-01 quando associados à adubação A1 (80\% de NPK). 
TABELA 1 - Resumo da análise de variância para a atividade da enzima redutase do nitrato em folhas de plantas do híbrido de mamoeiro UENF/CALIMAN-01 cultivadas em três diferentes espaçamentos entre plantas $(\mathrm{E} 1=1,80 \mathrm{~m}, \mathrm{E} 2=2,25$ e E3 $=2,70 \mathrm{~m})$, cinco níveis de adubação NPK (A1 $=80 \%$ do padrão, $\mathrm{A} 2=100 \%$ do padrão da empresa, $\mathrm{A} 3=120 \%$ do padrão, $\mathrm{A} 4=140 \%$ do padrão e A5 $=160 \%$ do padrão NPK) e cinco períodos de avaliação (meses de março a julho).

\begin{tabular}{lcc}
\hline \multicolumn{1}{c}{ Fontes de variação } & GL & QM (Redutase do Nitrato) \\
\hline Bloco & 3 & 4821,42 \\
Espaçamento & 2 & $\mathbf{2 2 5 8 6 8 , 5 9 *}$ \\
Período & 4 & $\mathbf{1 1 0 5 0 7 1 , 1 2 *}$ \\
Adubação & 4 & 11698,73 \\
EspaçamentoxPeríodo & 8 & $\mathbf{5 3 3 0 5 , 4 1 *}$ \\
EspaçamentoxAdubação & 8 & 32101,48 \\
PeríodoxAdubação & 16 & 29500,92 \\
EspaçamentoxPeríodoxAdubação & 32 & 28376,66 \\
Resíduo & 222 & 24562,40 \\
Total & 299 & \\
CV (\%) & - & 43,00 \\
Média & - & 364,19 \\
\hline
\end{tabular}

* valores significativos ao nível de $5 \%$ de probabilidade, pelo teste $\mathrm{F}$

TABELA 2 - Média da atividade da enzima redutase do nitrato (nmoles de $\mathrm{NO}_{2}^{-} \mathrm{h}^{-1} \mathrm{~g}^{-1}$ de matéria fresca) nas folhas de plantas do híbrido de mamoeiro UENF/CALIMAN-01 cultivadas em três diferentes espaçamentos entre plantas $(\mathrm{E} 1=1,80 \mathrm{~m}, \mathrm{E} 2=2,25$ e E3 $=2,70 \mathrm{~m})$, cinco níveis de adubação NPK $(A 1=80 \%$ do padrão, $\mathrm{A} 2=100 \%$ do padrão da empresa, $\mathrm{A} 3=120 \%$ do padrão, $\mathrm{A} 4=140 \%$ do padrão e A5 = 160\% do padrão NPK) e cinco períodos de avaliação (meses de março a julho).

\begin{tabular}{|c|c|c|c|c|c|c|}
\hline RN (março) & & & Adubação & & & \\
\hline Espaçamento & A1 $(80 \%)$ & A2 $(100 \%)$ & A3 $(120 \%)$ & A4 (140\%) & A5 $(160 \%)$ & Médias \\
\hline E1 $(1,80 \mathrm{~m})$ & $572 \mathrm{aC}$ & $574 \mathrm{aB}$ & $577 \mathrm{aA}$ & $452 \mathrm{aE}$ & $508 \mathrm{aD}$ & 537 \\
\hline E2 $(2,25 \mathrm{~m})$ & $357 \mathrm{aC}$ & $411 \mathrm{abA}$ & $309 \mathrm{bE}$ & $359 \mathrm{aB}$ & $337 \mathrm{aD}$ & 355 \\
\hline E3 $(2,70 \mathrm{~m})$ & $375 \mathrm{aD}$ & $311 \mathrm{bE}$ & $398 \mathrm{abB}$ & $378 \mathrm{aC}$ & $423 \mathrm{aA}$ & 377 \\
\hline Médias & 435 & 432 & 428 & 396 & 423 & 423 \\
\hline RN (abril) & & & Adubação & & & \\
\hline Espaçamento & A1 $(80 \%)$ & A2 $(100 \%)$ & A3 $(120 \%)$ & A4 (140\%) & A5 (160\%) & Médias \\
\hline E1 $(1,80 \mathrm{~m})$ & 226 aA & 106 aA & $126 \mathrm{aA}$ & 399 aA & 241abA & 220 \\
\hline E2 $(2,25 \mathrm{~m})$ & $245 \mathrm{aA}$ & $120 \mathrm{aA}$ & $121 \mathrm{aA}$ & $103 \mathrm{bA}$ & $127 \mathrm{bA}$ & 143 \\
\hline E3 $(2,70 \mathrm{~m})$ & $174 \mathrm{aA}$ & $102 \mathrm{aA}$ & $115 \mathrm{aA}$ & $355 \mathrm{abA}$ & $392 \mathrm{aA}$ & 228 \\
\hline Médias & 215 & 109 & 121 & 286 & 253 & 197 \\
\hline RN (maio) & & & Adubação & & & \\
\hline Espaçamento & A1 $(80 \%)$ & A2 $(100 \%)$ & A3 $(120 \%)$ & A4 (140\%) & A5 $(160 \%)$ & Médias \\
\hline E1 $(1,80 \mathrm{~m})$ & 392 aB & $358 \mathrm{aB}$ & $444 \mathrm{aAB}$ & $551 \mathrm{aAB}$ & 713 aA & 491 \\
\hline E2 $(2,25 \mathrm{~m})$ & $461 \mathrm{aA}$ & $404 \mathrm{aA}$ & $440 \mathrm{aA}$ & 418 aA & $446 \mathrm{bA}$ & 434 \\
\hline E3 $(2,70 \mathrm{~m})$ & $475 \mathrm{aA}$ & $483 \mathrm{aA}$ & $367 \mathrm{aA}$ & $240 \mathrm{aA}$ & $377 \mathrm{bA}$ & 388 \\
\hline Médias & 442 & 415 & 417 & 403 & 512 & 438 \\
\hline RN (junho) & & & Adubação & & & \\
\hline Espaçamento & A1 $(80 \%)$ & A2 (100\%) & A3 $(120 \%)$ & A4 (140\%) & A5 $(160 \%)$ & Médias \\
\hline E1 $(1,80 \mathrm{~m})$ & $550 \mathrm{aA}$ & $601 \mathrm{aA}$ & $486 \mathrm{aA}$ & $573 \mathrm{aA}$ & $685 \mathrm{aA}$ & 579 \\
\hline E2 $(2,25 \mathrm{~m})$ & $488 \mathrm{aA}$ & $556 \mathrm{aA}$ & $578 \mathrm{aA}$ & $320 \mathrm{aA}$ & $330 \mathrm{bA}$ & 455 \\
\hline E3 $(2,70 \mathrm{~m})$ & $407 \mathrm{aA}$ & $613 \mathrm{aA}$ & $387 \mathrm{aA}$ & $526 \mathrm{aA}$ & $548 \mathrm{abA}$ & 496 \\
\hline Médias & 482 & 590 & 484 & 473 & 521 & 510 \\
\hline RN (julho) & & & Adubação & & & \\
\hline Espaçamento & A1 $(80 \%)$ & A2 (100\%) & A3 (120\%) & A4 (140\%) & A5 (160\%) & Médias \\
\hline E1 $(1,80 \mathrm{~m})$ & $133 \mathrm{aA}$ & $358 \mathrm{aA}$ & $258 \mathrm{aA}$ & $273 \mathrm{aA}$ & $160 \mathrm{aA}$ & 236 \\
\hline E2 $(2,25 \mathrm{~m})$ & $153 \mathrm{aA}$ & $230 \mathrm{aA}$ & $244 \mathrm{aA}$ & $235 \mathrm{bA}$ & $147 \mathrm{aA}$ & 202 \\
\hline E3 $(2,70 \mathrm{~m})$ & $383 \mathrm{aA}$ & $364 \mathrm{aA}$ & 349 aA & $259 \mathrm{abA}$ & $310 \mathrm{aA}$ & 333 \\
\hline Médias & 223 & 317 & 284 & 256 & 206 & 257 \\
\hline
\end{tabular}

Médias seguidas de uma mesma letra indicam que não houve diferença significativa, ao nível de $5 \%$ de probabilidade, pelo teste Tukey, entre as adubações (maiúsculas) e entre os espaçamentos (minúsculas). 
TABELA 3 - Dados climáticos de temperatura, umidade relativa do ar e precipitação da área experimental onde foram cultivadas plantas do híbrido de mamoeiro UENF/CALIMAN-01, em três diferentes espaçamentos entre plantas ( $\mathrm{E} 1=1,80 \mathrm{~m}, \mathrm{E} 2=2,25$ e E3 =2,70 m), cinco níveis de adubação NPK $(A 1=80 \%$ do padrão, $\mathrm{A} 2=100 \%$ do padrão da empresa, $\mathrm{A} 3=120 \%$ do padrão, $\mathrm{A} 4=140 \%$ do padrão e A5 $=160 \%$ do padrão NPK) e cinco períodos de avaliação (meses de março a julho).

\begin{tabular}{ccccc}
\hline Mês/ano & Dias & Média da Temperatura $\left({ }^{\circ} \mathrm{C}\right)$ & Média da Umidade relativa (\%) & Precipitação $(\mathrm{mm})$ \\
\hline dez/06 & 31 & 25,18 & 95,2 & 274,60 \\
$\mathrm{jan} / 07$ & 31 & 26,18 & 94,1 & 154,60 \\
$\mathrm{fev} / 07$ & 28 & 25,21 & 94,8 & 300,20 \\
$\mathrm{mar} / 07$ & 31 & 25,90 & 92,5 & 54,40 \\
$\mathrm{abr} / 07$ & 30 & 24,77 & 94,9 & 118,40 \\
$\mathrm{mai} / 07$ & 31 & 22,21 & 93,9 & 33,60 \\
$\mathrm{jun} / 07$ & 30 & 21,10 & 93,0 & 14,40 \\
$\mathrm{jul} / 07$ & 31 & 21,24 & 92,7 & 8,60 \\
$\mathrm{ago} / 07$ & 31 & 20,88 & 92,5 & 76,60 \\
$\mathrm{set} / 07$ & 30 & 21,30 & 92,2 & 52,60 \\
out $/ 07$ & 31 & 23,42 & 90.4 & 21.60 \\
\hline Total & 335 & 23,4 & 93,3 & 1109,6 \\
\hline
\end{tabular}

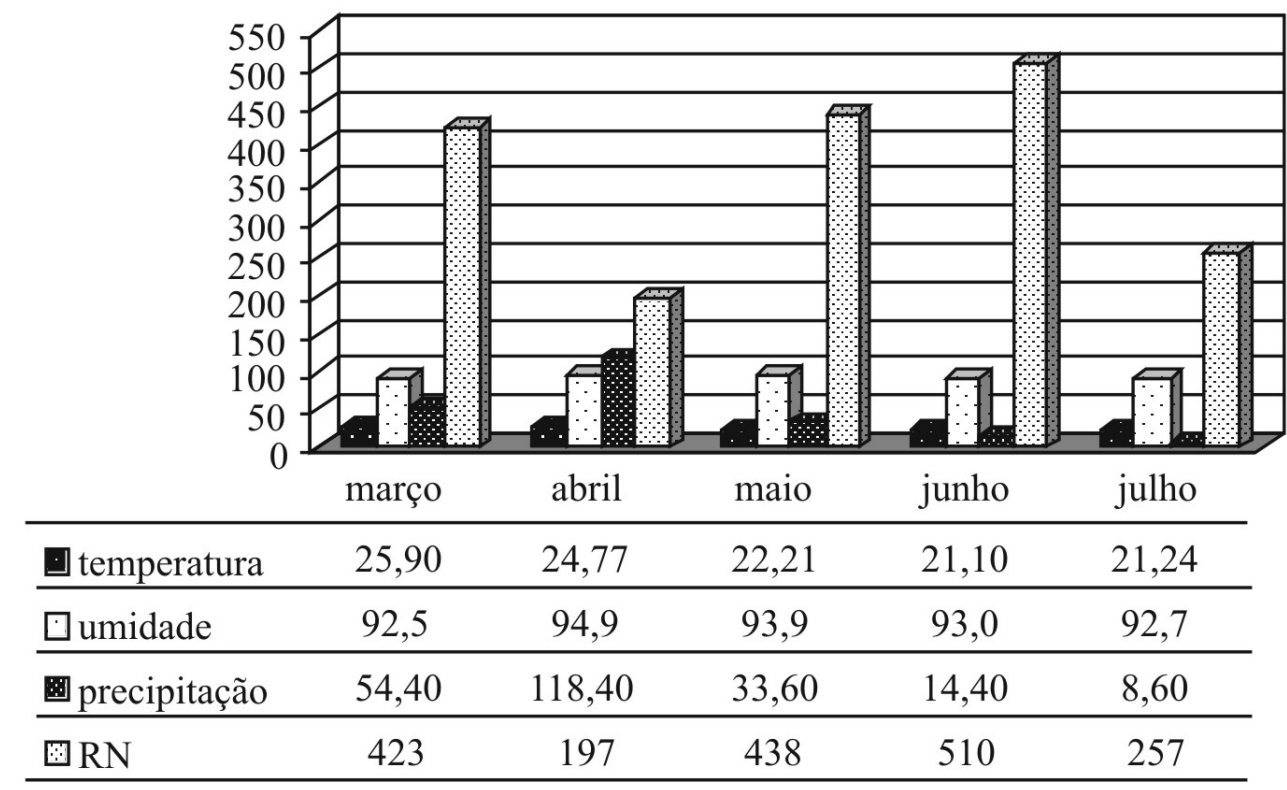

FIGURA 1 - Médias da temperatura, umidade relativa e precipitação local e da atividade da enzima redutase do nitrato (nmoles de $\mathrm{NO}_{2}^{-} \mathrm{h}^{-1} \mathrm{~g}^{-1}$ de matéria fresca) nas folhas de plantas do híbrido de mamoeiro UENF/CALIMAN-01 cultivadas em três diferentes espaçamentos entre plantas $(\mathrm{E} 1=1,80 \mathrm{~m}, \mathrm{E} 2=2,25$ e E3 $=2,70 \mathrm{~m})$, cinco níveis de adubação NPK $(\mathrm{A} 1=80 \%$ do padrão, $\mathrm{A} 2=100 \%$ do padrão da empresa, A3 $=120 \%$ do padrão, A $4=140 \%$ do padrão e A5 $=160 \%$ do padrão NPK) e cinco períodos de avaliação (meses de março a julho). 


\section{CONCLUSÃO}

Dentre os tratamentos testados, o nível A1 (80\% do padrão da empresa), independentemente dos espaçamentos, poderia ser indicado no manejo de adubação nitrogenada para o híbrido de mamoeiro UENF/CALIMAN-01, pois em todos eles a atividade da redutase do nitrato em, praticamente, todos os períodos avaliados, apresenta valores adequados, ou até mesmo superiores aos encontrados na literatura em cultivares de mamoeiro. A redução da adubação NPK pode ser justificada, uma vez que não há diferença na produtividade das plantas entre os tratamentos avaliados.

\section{AGRADECIMENTOS}

À empresa Caliman Agrícola, à FINEP, ao $\mathrm{CNPq}$ e à FAPERJ, pelo apoio logístico e financeiro para a condução das pesquisas.

\section{REFERÊNCIAS}

ANDRADE NETTO, J. F. de. Atividade das enzimas redutase do nitrato e glutamina sintetase em cafeeiro arábica. 2005. 60 f. Dissertação (Mestrado em Agronomia) - Escola Superior de Agricultura "Luiz de Queiroz", Universidade de São Paulo, Piracicaba, 2005.

BERNARDO, S.; CARVALHO, J. A.; SOUSA, E. F. Irrigação do mamoeiro. Campos dos Goytacazes: UENF, 1996. 20p. (Boletim Técnico, 5).

BREDEMEIER, C.; MUNDSTOCK, C. M. Regulação da absorção e assimilação do nitrogênio nas plantas. Ciência Rural, Santa Maria, v. 30, n. 2, p. 365-372, 2000.

CARELLI, M. L. C.; UNGARO, M. R. G.; FAHL, J. I.; NOVO, M. C. S. S. Níveis de nitrogênio, metabolismo, crescimento e produção de girassol. Revista Brasileira de Fisiologia Vegetal, v. 8, n. 2, p. 123-130, 1996.

CRUZ, C. D. Programa genes: estatística experimental e matriz. Viçosa: UFV, 2006. 346p.

DONATO, V.M.T.S.; ANDRADE, A.G.; SOUZA, E.S..; FRANÇA, J.G.E.; MACIEL, G.A. Atividade enzimática em variedades de cana-de-açúcar cultivadas in vitro sob diferentes níveis de nitrogênio. Pesquisa Agropecuária Brasileira, Brasília, v.39, n.11, p.1087-1093, 2004.
FERREIRA, V.M.; MAGALHÃES, P.C.; DURÃES, F.O.M.; OLIVEIRA, L.E.M.; PURCINO, A.A.C. Metabolismo do nitrogênio associado à deficiência hídrica e sua recuperação em genótipos de milho. Ciência Rural, Santa Maria, v.32, n.1, p. 13-17, 2002.

FONTES, R. V. Eficiência fotossintética e sua correlação com a variação diurna da atividade da redutase do nitrato em plantas de mamão (Carica papaya L. cv. Sunrise Solo). 2003. 26 f. Monografia (Graduação em Ciências Biológicas) - Universidade Federal do Espírito Santo, Vitória, 2003.

FONTES, R.V. Eficiência fotoquímica das plantas e atividade da enzima pectinametilesterase na polpa de frutos de mamoeiro (Carica papaya L.). 2005. 63f. Dissertação (Mestrado em Biologia Vegetal) - Universidade Federal do Espírito Santo, Vitória, 2003.

FONTES, R. V.; SANTOS, M. P.; FALQUETO, A. R.; SILVA, D. M. Atividade da redutase do nitrato e fluorescência da clorofila a em mamoeiro. Revista Brasileira de Fruticultura, Jaboticabal, v.30, n.1, p.251-254, 2008.

GALON, C. Z.; SILVA, D. M. Crescimento inicial e atividade da redutase do nitrato em plantas de mamão (Carica papaya L.) cv. Golden e Sunrise Solo. Revista Brasileira de Fisiologia Vegetal, Campinas, v.13, p.01-04, 2001. Suplemento.

GOMES FILHO, A. Ocorrência da mancha fisiológica do mamão (Carica papaya $\mathrm{L}$.) sob diferentes lâminas de irrigação e coberturas de solo. 2005. 90f. Dissertação. (Mestrado em Produção Vegetal) - Universidade Federal do Norte Fluminense Darcy Ribeiro, Rio de Janeiro, 2005.

JAWORSKI, E. G. Nitrate reductase assay in intact plant tissues. Biochemical and Biophysical Research Communications, Orlando, v.43, n.6, p.1274-1279, 1971.

KAISER, W. M.; HUBER, S. C. Post-translational regulation of nitrate reductase: mechanism, physiological relevance and environmental triggers. Journal Experimental Botany, Oxford, v.52, p.1980-1989, 2001. 
LYRA, G. B. Estimativa dos níveis ótimos econômicos de irrigação e de adubação nitrogenada nos mamoeiros (Carica papaya $\mathrm{L}$.) cultivar golden e do híbrido UENF Caliman 01. 2007. 160f. Tese (Doutorado em Produção Vegetal) - Universidade Federal do Norte Fluminense Darcy Ribeiro, Rio de Janeiro, 2007.

MARINHO, A. B. Respostas dos mamoeiros cultivar Golden e do híbrido Uenf/Caliman 01 sob diferentes lâminas de irrigação e doses de potássio. 2007. 125f. Tese (Doutorado em Produção Vegetal) - Universidade Federal do Norte Fluminense Darcy Ribeiro, Rio de Janeiro, 2007.

NIEVOLA, C. C.; MERCIER, H. Variações diurnas da atividade in vivo da redutase do nitrato em abacaxizeiro (Ananas comosus (L.) Merr. - Bromeliaceae). Revista Brasileira de Botânica, São Paulo, v. 24, n.3, p.295-301, 2001.

RESENDE, G. M.; COSTA, N. D. Características produtivas da melancia em diferentes espaçamentos de plantio. Horticultura Brasileira, Campinas, v. 21, n. 4, p. 695-698, 2003.
ROLIM, S.G.; COUTO, H.T.Z.; JESUS, R.M. Mortalidade e recrutamento de árvores na Floresta Atlântica de Linhares (ES). Scientia Florestalis, Piracicaba, v.55, p.49-69, 1999.

SCARPARE FILHO, J. A.; KLUGE, R. A. Produção da bananeira 'Nanicão' em diferentes densidades de plantas e sistemas de espaçamento. Pesquisa Agropecuária Brasileira, Brasília, v.36, n. 1, p. 105-113, 2001.

SIAG - Sistema de Informações Agrometereológico do Estado do Espírito Santo. Disponível em: $<\mathrm{http}: / /$ www.siag.incaper.es.gov.br>. Acesso em: dez. 2006.

TAIZ, L.; ZEIGER, E. Fisiologia vegetal. Porto Alegre: ARTMED, 2006. 719p.

TRINDADE, A. V. Mamão: Produção: aspectos técnicos. Cruz das Almas: Embrapa Mandioca e Fruticultura, 2000. 77p. (Frutas do Brasil, 3). 